\title{
Gas Phase Chromatography Experiments with Bromides of Tantalum and Element 105
}

\author{
By H. W. Gäggeler, D. T. Jost, J. Kovacs, U. W. Scherer, A. Weber, D. Vermeulen \\ Paul Scherrer Institut, $\mathrm{CH}-5232$ Villigen, Switzerland
}

A. Türler, K. E. Gregorich, R. A. Henderson, K. R. Czerwinski, B. Kadkhodayan, D. M. Lee, M. Nurmia, D. C. Hoffman

Lawrence Berkeley Laboratory, Berkeley, CA 94720, USA

J. V. Kratz, M. K. Gober, H. P. Zimmermann

Institut für Kernchemie, Universität Mainz, D-6500 Mainz, Federal Republic of Germany

M. Schädel, W. Brüchle, E. Schimpf

Gesellschaft für Schwerionenforschung mbH, D-6100 Darmstadt, Federal Republic of Germany

and I. Zvara

Joint Institute for Nuclear Research, Dubna, USSR

(Received October 28, 1991)

Element 105 / Transition metal group V / Chemical properties / Bromides / Volatility / Gas chromatography

\begin{abstract}
The retention behavior of volatile bromide molecules of shortlived isotopes of tantalum and element 105 in $\mathrm{KCl}$ coated quartz columns was studied using continuous isothermal gas chromatography. $\mathrm{HBr}$ and $\mathrm{HBr}$ saturated with $\mathrm{BBr}_{3}$ vapor were used as reactive gases. The isotopes were produced in the fusion reactions ${ }^{20} \mathrm{Ne}+{ }^{\text {nat. }} \mathrm{Eu}$ and ${ }^{18} \mathrm{O}+{ }^{249} \mathrm{Bk}$, respectively. The reaction products were transported from the accelerator to the chromatography set-up with a gas-jet system using an aerosol with $\mathrm{He}$ as carrier gas and $\mathrm{KCl}$ as transporting particles. The measured retention times are compared to those of ${ }^{99} \mathrm{~g} \mathrm{Nb}$ bromides from a previous study. The retention times of niobium and tantalum bromides are very similar, in agreement with expectations based on the nearly identical sublimation enthalpies of $\mathrm{NbBr}_{5}$ and $\mathrm{TaBr}_{5}$. For the bromides of element 105, higher retention times are found, indicating a lower volatility of $105 \mathrm{Br}$, than of $\mathrm{NbBr}_{5}$ and $\mathrm{TaBr}_{5}$. On the basis of empirical systematics, a sublimation enthalpy of $138 \pm 15 \mathrm{~kJ} / \mathrm{mol}$ can be estimated for $105 \mathrm{Br}_{5}$ from the experimental data.
\end{abstract}

\section{Introduction}

Recently, considerable interest has been drawn to the chemical properties of the heaviest elements. At very high atomic numbers, relativistic effects influence the electronic structure of the atoms even for valence electrons $[1-6]$. Calculations, taking relativistic terms into account, show a strong stabilization of shells with low angular momenta such as the spherical $s$ and $p_{1 / 2}$ orbitals. Based on this, it was suggested that lawrencium (Lr) and element 104 might behave like volatile $p$-elements [4]. This would be in contrast to expectations based on their positions in the periodic table of elements which would indicate that $\mathrm{Lr}$ should behave like an actinide and element 104 like a transition metal of group 4. However, no experimental evidence for a $p$-element behavior in $\operatorname{Lr}[7,8]$ or element 104 [9] has been found so far.

Recently, relativistic self-consistent Dirac-Slater calculations have been performed for chemical species of element 105. Properties of compounds of element 105 in aqueous solution [10] as well as for gaseous halides [11] were calculated. It was predicted that, e.g., the pentachlorides and pentabromides of element 105 should be more volatile than those of its chemical homologs of the transitions metals of group $5, \mathrm{Nb}$ and Ta [11].

These theoretical predictions have stimulated experimental efforts to search for "relativistic effects" in the chemical behavior of the heaviest elements. However, such investigations are extremely difficult because only a few atoms of short-lived isotopes can be produced at heavy ion accelerators. Under these conditions, the classical law of mass action is not $a$ priori valid [12]. In addition, if the kinetics of the chemical reactions are too slow the volatile molecules cannot be formed in due time [13]. This necessitates investigations with molecules of chemical homologs with similar volatility which are also produced at subtracer levels. In addition, thermodynamic properties, such as sublimation or evaporation enthalpies, boiling and melting points etc. cannot be measured in singleatom chemistry. However, it has been shown [14], that correlations exist between macrochemical quantitites, such as the boiling point or the sublimation enthalpy, and the microchemical quantity adsorption enthalpy. In gas phase chemistry experiments, adsorption en- 
thalpies of single atoms or molecules with the surface of the chromatography columns can be determined, either by measuring the deposition temperature in a thermochromatographic column [15] or by determining the retention time in an isothermal column [16].

The heaviest element whose chemical properties have been investigated is element 105 . Early studies were performed by Zvara et al. $[17,18]$ with volatile chlorides and bromides in gas thermochromatography experiments. They showed that these halides deposit in glass and nickel columns at temperatures significantly higher than those of the same compounds of niobium. The authors concluded that $105 \mathrm{Cl}_{5}$ and $105 \mathrm{Br}_{5}$ are less volatile than $\mathrm{NbCl}_{5}$ and $\mathrm{NbBr}_{5}$, respectively. However, in order to compare the experimentally determined deposition temperatures for compounds of niobium and of element 105 some theoretical calculations were needed to take account of the very large differences in half-lives of the nuclides used $\left({ }^{90} \mathrm{Nb}\right.$ with $T_{1 / 2}=14.6 \mathrm{~h}$ and ${ }^{261} 105$ with $T_{1 / 2}=1.8 \mathrm{~s}$ ). Recently, these results were confirmed by additional measurements [19].

Gregorich et al. [20] and Kratzet al. [21] performed first studies in the aqueous phase and showed that element 105 has properties which are typical for a transition metal of group 5 such as a pronounced sorption on glass surfaces from concentrated nitric acid solution [22]. Experiments to study the extraction behavior from mineral acid solutions into methyl isobutyl ketone [20] and triisooctyl amine [21] showed that element 105 behaves similarly to niobium and not like its direct homolog in the periodic table, tantalum. This surprising result was the object of further studies which were performed with diisobutylcarbinol as extractant [23].

In the current work the gas chromatographic behavior of the bromides of tantalum and element 105 in $\mathrm{KCl}$ covered quartz columns was studied. Some of the results were presented earlier [24, 25]. All experiments were performed with the chromatography system OLGA II [26]. This device allows the determination of retention times of volatile species in isothermal columns by using the half-lives of the nuclides as a "clock" [16].

\section{Experimental}

Element 105 was produced at the LBL 88-inch cyclotron in the ${ }^{18} \mathrm{O}+{ }^{249} \mathrm{Bk}$ reaction. A $114-\mathrm{MeV}{ }^{18} \mathrm{O}^{5+}$ beam passed through a $1.8 \mathrm{mg} / \mathrm{cm}^{2}$ HAVAR window foil, $0.2 \mathrm{mg} / \mathrm{cm}^{2}$ of $\mathrm{N}_{2}$ cooling gas and a $2.49 \mathrm{mg} / \mathrm{cm}^{2}$ Be target backing foil before it entered the $0.54 \mathrm{mg} /$ $\mathrm{cm}^{2}$ thick ${ }^{249} \mathrm{Bk}$ (as an oxide) target. The experiments were performed less than 75 days after the Bk was chemically separated from Cf. Hence, only a small fraction of the $330-\mathrm{d}{ }^{249} \mathrm{Bk}$ had decayed into ${ }^{249} \mathrm{Cf}$. The calculated ${ }^{18} \mathrm{O}$ energy in the target was 98 to $99 \mathrm{MeV}$. At this bombarding energy the nuclides ${ }^{262} 105$ and ${ }^{263} 105$ from the $5 n$ and $4 n$ reaction chan- nels are produced with cross sections of $6 \pm 3 \mathrm{nb}$ and $2 \pm 1 \mathrm{nb}$, respectively [27]. ${ }^{262} 105$ has a half-life of $34 \mathrm{~s}$ and decays by $\alpha$-emission (67\%) and by spontaneous fission (SF) $(33 \%)[27,33] .{ }^{263} 105$ has a half-life of $27 \mathrm{~s}$ and decays by $\alpha$-emission ( $43 \%)$ and by SF (57\%) [27]. Hence, at our bombarding energy the total cross sections for production of $\alpha$-decaying isotopes of element 105 is $4.9 \mathrm{nb}$, and that of SF decaying isotopes of element 105 is $3.1 \mathrm{nb}$. Typical beam currents applied to the target were 0.5 particle $\mu \mathrm{A}$ of ${ }^{18} \mathrm{O}$.

Tantalum isotopes were produced at the same cyclotron using the reaction ${ }^{20} \mathrm{Ne}+{ }^{\text {nal }} \mathrm{Eu}$ (approx. $0.25 \mathrm{mg} / \mathrm{cm}^{2}$ on $4.5 \mathrm{mg} / \mathrm{cm}^{2} \mathrm{Be}$ ). Actual beam currents were 0.07 to 0.15 particle $\mu \mathrm{A}$. The same set-up was used as above and the ${ }^{20} \mathrm{Ne}$ energy in the target was $143 \mathrm{MeV}$. The experiments were performed with the isotopes ${ }^{164} \mathrm{Ta}\left(T_{1 / 2}=20 \mathrm{~s}\right),{ }^{166} \mathrm{Ta}\left(T_{1 / 2}=32 \mathrm{~s}\right)$, and ${ }^{167} \mathrm{Ta}\left(T_{1 / 2}=78 \mathrm{~s}\right)$.

The reaction products recoiling out of the target were stopped in a collection chamber which was continuously flushed with a $\mathrm{He}$ gas-jet loaded with $\mathrm{KCl}$ particles at a rate of about $1 \mathrm{l} / \mathrm{min} \mathrm{He}$. The $\mathrm{KCl}$ particles were generated in an oven kept at $680^{\circ} \mathrm{C}$ by passing the carrier gas (He) over a porcelain boat containing the $\mathrm{KCl}$.

The pressure in the target recoil chamber was about 1.3 bar. The products of nuclear reactions recoiling from the target attached to the $\mathrm{KCl}$ aerosol particles and were transported through a $2 \mathrm{~mm}$ I.D. and about $10 \mathrm{~m}$ long polyethylene capillary to the gas chromatography set-up. A schematic drawing [26] of the gas chromatography and counting device is shown in Fig. 1. Reaction products were stopped on a quartz wool plug $(l=5 \mathrm{~mm})$ inserted into an empty quartz tube (I.D. $=6 \mathrm{~mm}, l=25 \mathrm{~cm}$ ). The tube ended in a $5 \mathrm{~cm}$ long capillary shaped exit $(\mathrm{I} . \mathrm{D} .=1 \mathrm{~mm})$. The column was placed in a five-section oven (HERAEUS). At the position of the quartz wool plug, the temperature was kept fixed at a value of about $900^{\circ} \mathrm{C}$, significantly above the melting point of $\mathrm{KCl}$ $\left(T_{\text {m.p. }}=770^{\circ} \mathrm{C}\right)$. All other sections of the oven formed an isothermal section in the quartz tube. The temperature of this isothermal section could be varied between 200 and $700^{\circ} \mathrm{C}$. Each experiment lasted typically 2 to 6 hours in case of element 105 and about $5 \mathrm{~min}$ for tantalum. At the position of the quartz wool plug, $100 \mathrm{ml} / \mathrm{min} \mathrm{HBr}_{\mathrm{g}}$ was added as brominating agent. This flow rate was found to be optimum [28]. In some experiments the $\mathrm{HBr}$ gas was mixed with $\mathrm{BBr}_{3}$ vapor by passing $\mathrm{HBr}$ over liquid $\mathrm{BBr}_{3}$ kept at $0^{\circ} \mathrm{C}$. Despite careful cleaning of all gases, boron oxide was formed with the trace amounts of oxygen in the system which probably entered the system via diffusion of air through the polyethylene transport capillary. This white powder deposited onto the walls of the capillary and lowered the transport yields of the products. Moreover, final samples had poor $\alpha$-resolutions.

In the experiments with element 105 , the quartz columns were pre-treated before each experiment by heating them for about $15 \mathrm{~min}$ in a flowing $\mathrm{HBr}$ gas 


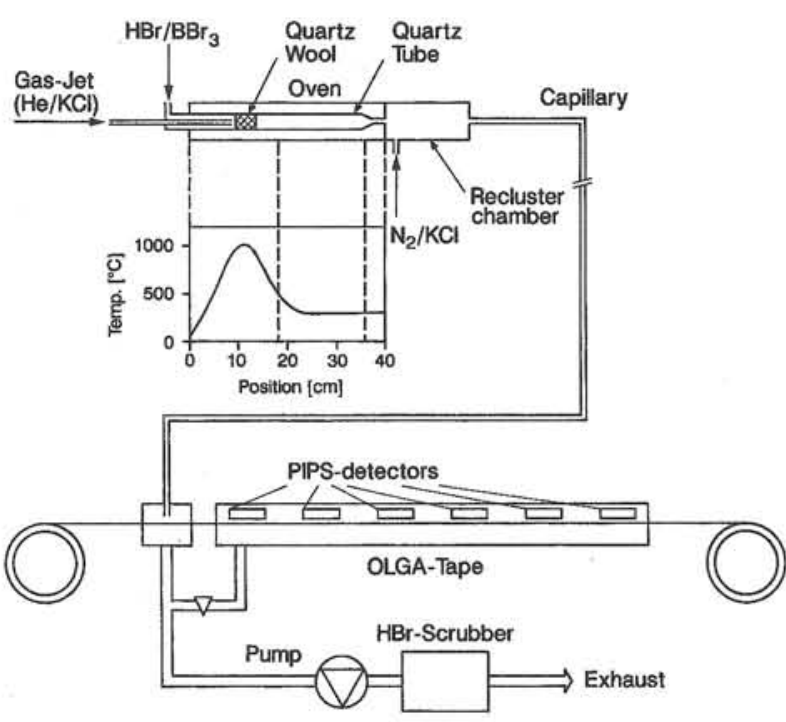

Fig. 1. Schematic drawing of the gas chemistry and counting device OLGA (On-Line Gas chemistry Apparatus). Products transported by a gas-jet system are continuously fed into a chromatography column $\left(\mathrm{SiO}_{2}\right)$ and collected on a quartz wool plug. By melting of the transporting particles $(\mathrm{KCl})$ and by interaction with a reactive gas (e.g., $\mathrm{HBr}$ ), volatile compounds are formed which are transported through an isothermal second part of the column and ejected into a recluster unit. By reattachment of these molecules on new particles they can be transported through a capillary to a tape system. Here the particles containing the separated molecules are deposited. From time to time the tape is moved stepwise to bring the deposited activity in front of PIPS detectors for $\alpha$ - and SF-counting.

and $\mathrm{He} / \mathrm{KCl}$ gas-jet at $700^{\circ} \mathrm{C}$. This treatment turned out to be necessary to obtain reproducible results.

In the experiments with tantalum reasonable yields were only obtained in experiments where the $\mathrm{HBr}$ gas contained $\mathrm{BBr}_{3}$ vapor.

After the chromatography column the volatile species were injected into a recluster chamber (I.D. = $7 \mathrm{~cm}, l=60 \mathrm{~cm}$ ). This unit was flushed with $2 l / \mathrm{min}$ $\mathrm{N}_{2}$ loaded with new $\mathrm{KCl}$ particles. The total gas (about $3.1 \mathrm{l} / \mathrm{min}$ ) containing the products under study attached to the $\mathrm{KCl}$ particles was then transported through a capillary (I.D. $=2 \mathrm{~mm}, 1=5 \mathrm{~m}$ ) to the counting device, a modified magnetic tape station. Here, in a collection chamber the products were deposited on the surface of a conventional computer tape. Every $30 \mathrm{~s}$ the tape was stepped to transport the activity in front of $450 \mathrm{~mm}^{2}$ PIPS (passivated ionimplanted planar silicon) detectors (CANBERRA) for $\alpha$ - and SF-counting. The data were stored in an eventby-event mode using CAMAC electronics connected to a $\mu$ VAX. Data transfer and analysis were performed with the PSI-TANDEM [29] and the CERN-PAW [30] software packages [31].

The distance between the end of the capillary and the tape surface was $6 \mathrm{~mm}$ [26]. The visible deposits on the tape $\left(\mathrm{KCl}\right.$ or $\left.\mathrm{B}_{2} \mathrm{O}_{3}\right)$ had $\leq 6 \mathrm{~mm}$ diameter. The distance between tape and detector surface was $3 \mathrm{~mm}$ and the efficiency for $\alpha$-counting was $38 \%$. By differential pumping, the pressures were kept at about 17 mbar in the collection chamber and $20 \mathrm{mbar}$ in the

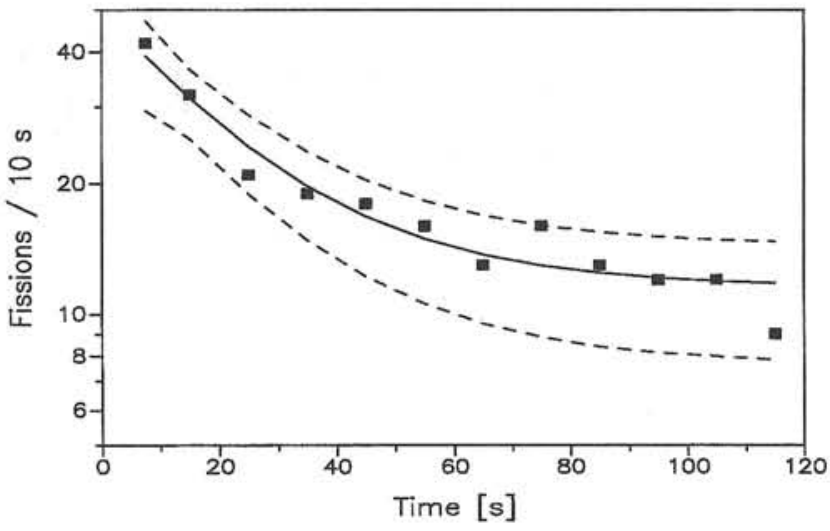

Fig. 2. Spontaneous fission activity measured in the ${ }^{18} \mathrm{O}+{ }^{249} \mathrm{Bk}$ reaction during a direct catch experiment with a beam dose of $8.7 \cdot 10^{16}$ particles. The fit to the data results in a short-lived component with $T_{1 / 2}=28 \pm 8 \mathrm{~s}$ and a long-lived component from ${ }^{256} \mathrm{Fm}$, produced in this reaction via ingrowth from ${ }^{256} \mathrm{Md}$ [32].

counting area. Due to the thickness of the tape $\left(6.7 \mathrm{mg} / \mathrm{cm}^{2}\right)$, it was only possible to perform $\alpha$ - and SF-counting from the front side of the tape.

For the chemistry experiments with tantalum, the counting device was identical to that used for the study of niobium [28]. It consisted of an aerosol particle absorbing glass fiber filter station mounted on top of a high purity Ge $\gamma$-ray detector for continuous monitoring of the $\gamma$-rays of the tantalum isotopes of interest.

\section{Results}

\subsection{Direct catch experiments}

During each series of experiments, one direct catch (DC) measurement was made. These measurements were used to normalize the chemical yields.

In the DC runs, the quartz column was empty and not heated. All gas flow rates were kept the same as in the chemistry experiments.

An absolute yield of the gas-jet transport system was not determined. However, based on some estimates made via $\alpha$-lines from long-lived actinides measured in the ${ }^{18} \mathrm{O}+{ }^{249} \mathrm{Bk}$ experiments [32], we obtained typical transport plus deposition yields on the tape of about $60 \pm 20 \%$.

The $\alpha$-particle spectra measured in the ${ }^{18} \mathrm{O}+{ }^{249} \mathrm{Bk}$ experiments showed mainly lines from short-lived isotopes of polonium and ${ }^{211} \mathrm{Bi}$. These nuclides were most likely produced in nucleon transfer reactions between ${ }^{18} \mathrm{O}$ and $\mathrm{a} \mathrm{Pb}$ contamination in the target. Unfortunately, the contamination was rather high and prevented a detection of the ${ }^{262} 105(8.45-8.67 \mathrm{MeV})$ $[27,33]$ and ${ }^{263} 105(8.35 \mathrm{MeV})[27] \alpha$-lines. The $\mathrm{Bi}$ and Po activities also obscured $\alpha-\alpha$ correlation measurements with the corresponding $\mathrm{Lr}$ daughter nuclides. Detection of ${ }^{262} 105$ and ${ }^{263} 105$ was therefore possible only via their SF decay. In Fig. 2 the SF-decay curve is shown which was accumulated during several DC 
runs with a total of $8.7 \cdot 10^{16}{ }^{18} \mathrm{O}$ ions. A twocomponent fit [34] results in a short-lived activity with a half-life of $28 \pm 8 \mathrm{~s}$, in agreement with the presence of ${ }^{262} 105$ and ${ }^{263} 105$, and a long-lived component which we attribute to ${ }^{256} \mathrm{Fm}$. Under the assumption of a gas-jet transport plus deposition yield of $60 \pm$ $20 \%$, the cross section of the short-lived component amounts to $4.1 \pm 1.6 \mathrm{nb}$. This cross section is in good agreement with the value of $3.1 \mathrm{nb}$ estimated above for the sum of the SF branches of ${ }^{262} 105$ plus ${ }^{263} 105$ at this bombarding energy. Kratz et al. [21] found for the same bombarding energy in the chemically separated element 105 fraction $a \approx 30 \mathrm{~s}$ SF activity with a cross section of $4 \mathrm{nb}$.

\subsection{Experiments with tantalum}

Fig. 3a through $3 \mathrm{c}$ show the chemical yields for different tantalum isotopes using $\mathrm{HBr}$ containing $\mathrm{BBr}_{3}$ vapor as reactive gas. In general, for temperatures above $100^{\circ} \mathrm{C}$ the yields increase and reach a plateau at about $300^{\circ} \mathrm{C}$. The absolute value of the maximum chemical yield is dependent on the half-life of the nuclide. This has already been observed in previous studies $[24,25,28]$. It can be explained by the time needed in the recluster unit for the molecules to reattach on new $\mathrm{KCl}$ particles before transport to the detector. This time was estimated to be 18 to $25 \mathrm{~s}$ $[24,25,28]$, in agreement with a value of about $20 \mathrm{~s}$ deduced from Fig. 3.

In Fig. 3b, the yield curve with pure $\mathrm{HBr}$ as reactive gas is also shown for ${ }^{166} \mathrm{Ta}$. For temperatures above $500^{\circ} \mathrm{C}$, slowly increasing yields are found which reach a value of only $15 \%$ at $750^{\circ} \mathrm{C}$. Both the shape of this curve and the low chemical yield values indicate that with pure $\mathrm{HBr}$ no quantitative bromination of tantalum can be achieved.

In Fig. 3d, the yield curve from Ref. [28] for 15-s ${ }^{99} \mathrm{~g} \mathrm{Nb}$ is shown. These measurements were performed with pure $\mathrm{HBr}$. In contrast to tantalum, pure $\mathrm{HBr}$ produces volatile niobium bromide molecules with high yields for temperatures $\geq 300^{\circ} \mathrm{C}$. Their retention behavior is very similar to that of tantalum bromide molecules formed with $\mathrm{HBr} / \mathrm{BBr}_{3}$ as reactive gas.

\subsection{Experiments with element 105}

In the first preliminary experiments [24] $\mathrm{HBr}$ containing $\mathrm{BBr}_{3}$ vapor was used as the reactive gas. However, due to the experimental problems caused by the deposition of $\mathrm{B}_{2} \mathrm{O}_{3}$ (see above) most of the studies described in this work were performed with pure $\mathrm{HBr}$. Only at two temperatures $\left(200\right.$ and $\left.400^{\circ} \mathrm{C}\right)$, additional experiments were made with $\mathrm{HBr}$ containing $\mathrm{BBr}_{3}$ vapor.

Monitoring the $\alpha$-count rates of polonium isotopes produced during the on-line experiment, we found that yield fluctuations of $\pm 20 \%$ occurred due to fluctuations of the transportation yields during the long measurements. We have therefore normalized the
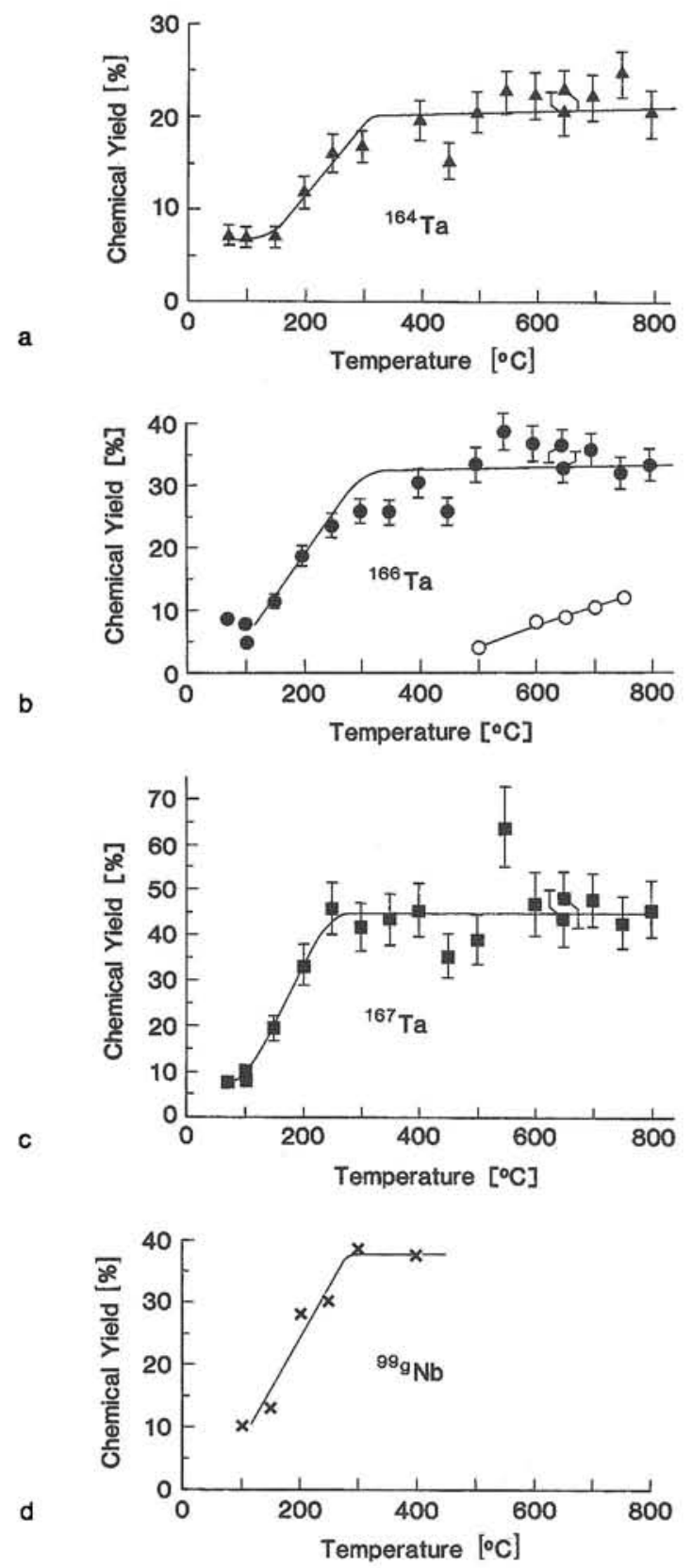

Fig. 3. Chemical yields for three isotopes of Ta behind a quartz column heated at different temperatures using a $\mathrm{He} / \mathrm{KCl}$ gas-jet transport system and $\mathrm{HBr}$ saturated with $\mathrm{BBr}_{3}$ vapor as reactive gas (Figs. 3a through 3c). The open circles in Fig. 3b depict data measured with pure $\mathrm{HBr}$. Fig. 3d shows the yield data for ${ }^{99{ }^{8}} \mathrm{Nb}$ from Ref. [28] measured with the same system. They were obtained with pure $\mathrm{HBr}$. The lines are drawn to guide the eye.

chemical yields of element 105 to those of 45-s ${ }^{212 \mathrm{~m} 2} \mathrm{Po}$. From a previous study [24] it is known that polonium forms volatile bromides with high, constant yields down to temperatures of about $300^{\circ} \mathrm{C}$.

The determination of the chemical yields of element 105 bromides was made by the measurement of the SF-decay of the isotopes ${ }^{262} 105$ and ${ }^{263} 105$. Fig. 4 summarizes the measured SF activity from the sum of all gas chemistry experiments. A short-lived activity with a half-life of $44_{-12}^{+19} \mathrm{~s}$ was found which agrees 


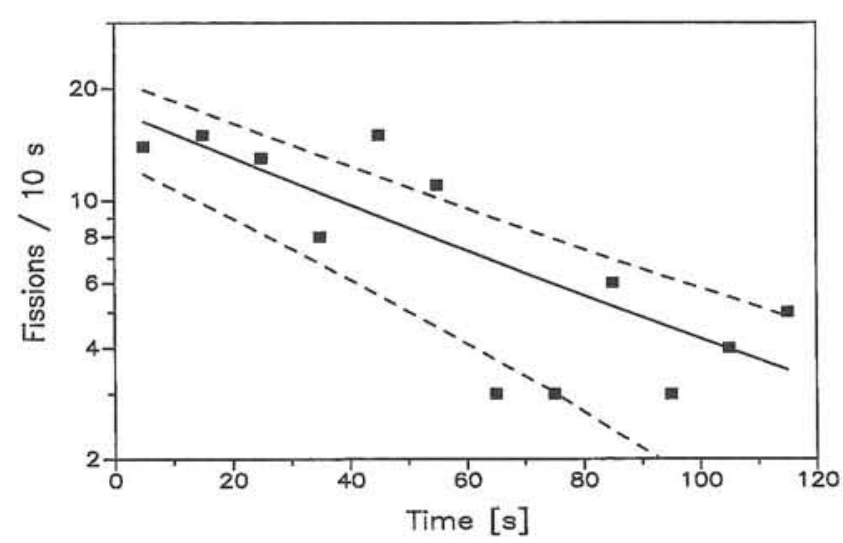

Fig. 4. Measured spontaneous fission events from all gas chemistry experiments. The solid line is a maximum likelihood fit to the data giving a half-life of $41 \pm 12 \mathrm{~s}$, with the $68 \%$ confidence limits indicated by the dashed line.

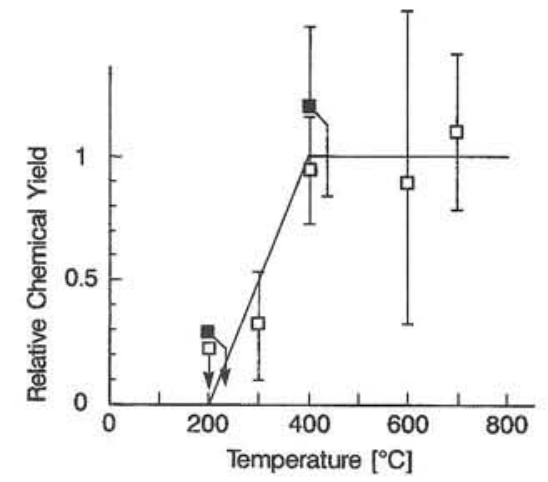

Fig. 5. Relative chemical yields for element 105 bromides with pure $\mathrm{HBr}$ as reactive gas as a function of the temperature of the isothermal part of the quartz chromatography column (open squares), and with $\mathrm{HBr}$ containing $\mathrm{BBr}_{3}$ vapor (closed squares). A relative chemical yield of 1 corresponds to an absolute chemical yield of $40 \pm 10 \%$

within the given error with the expected value of $\approx 30 \mathrm{~s}$.

In Fig. 5, the relative chemical yields of element 105 bromides are shown for the temperature range 200 to $700^{\circ} \mathrm{C}$. The relative chemical yield of 1 corresponds to an absolute chemical yield of $40 \pm 10 \%$. The errors given in Fig. 5 represent statistical uncertainties only. For the yield values at, e.g., $400^{\circ} \mathrm{C}$ and $700^{\circ} \mathrm{C}$ the total SF-count rates were $20(11 / 6 / 3 / 0$ events in detectors $1 / 2 / 3 / 4$ at 30 s steps) and $19(7 / 7 / 3 / 2)$, respectively.

In a single run, we tried to form volatile chlorides with $\mathrm{HCl}$ gas instead of $\mathrm{HBr}$. For a gas flow rate of $100 \mathrm{ml} / \mathrm{min} \mathrm{HCl}$ and a temperature of $700^{\circ} \mathrm{C}$ no formation of volatile 105 chlorides was observed.

\section{Discussion}

Figure 6 summarizes the results from this work, those for niobium bromides with pure $\mathrm{HBr}$ [28], and for element 105 bromides with $\mathrm{HBr}$ containing $\mathrm{BBr}_{3}$ vapor [24]. From the results of element 105 bromides from Ref. [24], only the yields at $T \leq 400^{\circ} \mathrm{C}$, averaged

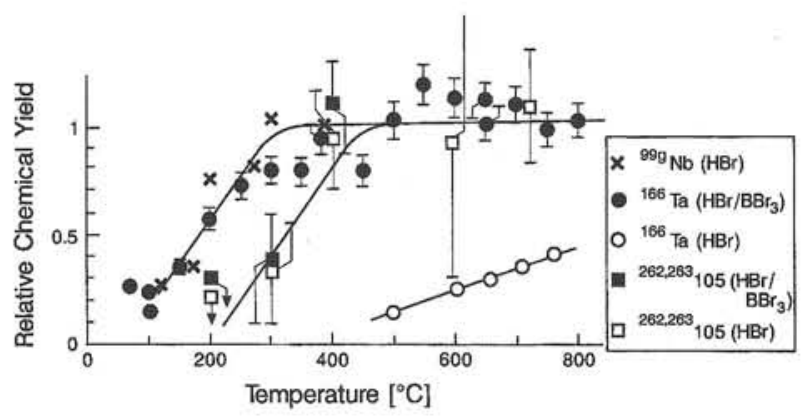

Fig. 6. Relative chemical yields for bromides of ${ }^{99} \mathrm{Nb}$ (from Ref. [28]) with pure $\mathrm{HBr}$ and of ${ }^{166} \mathrm{Ta}$ and ${ }^{262} 105$ plus ${ }^{263} 105$ with pure $\mathrm{HBr}$, and with $\mathrm{HBr}$ containing $\mathrm{BBr}_{3}$ vapor, respectively. Also shown are the results from Ref. [24] for element 105 bromides with $\mathrm{HBr}$ containing $\mathrm{BBr}_{3}$ vapor at 300 and $400^{\circ} \mathrm{C}$. The value at $400^{\circ} \mathrm{C}$ was averaged with the result from this work (see Fig. 5).

with the results from this work, are shown. At higher temperatures the yields dropped because of a nonoptimum diameter of the exit capillary of the chromatography column (see Refs. [26, 28]).

The curves for niobium bromides with $\mathrm{HBr}$ and tantalum bromides with $\mathrm{HBr} / \mathrm{BBr}_{3}$ are very similar. This is in line with the nearly identical values of the boiling points or sublimation enthalpies for $\mathrm{NbBr}_{5}$ and $\mathrm{TaBr}_{5}$. They are 356 and $344^{\circ} \mathrm{C}$, and 111 and $106 \mathrm{~kJ} / \mathrm{Mol}$, respectively [35]. However, on the basis of our study, no conclusive answer to the question can be given whether the pure bromide molecules or the oxy-bromide molecules are formed. It can be expected that the properties of $\mathrm{NbOBr}_{3}$ and $\mathrm{TaOBr}_{3}$ molecules should also be very similar, though no detailed literature data exist. However, since with the very strong brominating agent $\mathrm{HBr} / \mathrm{BBr}_{3} \mathrm{Ta}$ behaves like $\mathrm{Nb}$, we believe that most likely the molecules transported along the column are the pentabromides rather than the oxy-bromides. It is interesting to note that bromination of niobium is easier to achieve than is that of tantalum.

The onset of increasing relative chemical yields for element 105 bromides is shifted by about $130 \pm 60^{\circ} \mathrm{C}$ towards higher temperatures compared to those of niobium and tantalum bromides. Also, with the strongly brominating agent $\mathrm{HBr} / \mathrm{BBr}_{3}$ the yield curve did not change compared to pure $\mathrm{HBr}$. This again supports the conclusion that most likely the molecule which we investigated in our work is $105 \mathrm{Br}_{5}$ and not any less volatile oxy-bromide [36]. From this result we conclude that element 105 bromide has a higher adsorption enthalpy on the surface of the columns than does $\mathrm{TaBr}_{5}$ or $\mathrm{NbBr}_{5}$. From this we conclude that $105 \mathrm{Br}_{5}$ is less volatile than $\mathrm{NbBr}_{5}$ and $\mathrm{TaBr}_{5}$. This is in agreement with thermochromatographic studies $[18,19]$, but disagrees with very recent theoretical predictions on the chemical properties of group 5 halides [11].

From the measured retention temperatures the adsorption enthalpy can be calculated using Eq. (1) [16]: 
Table 1. Adsorption enthalpies $\left(\Delta H_{a}\right)$ for niobium, tantalum, and element 105 bromides in the $\mathrm{KCl}$ coated quartz columns, and determination of the sublimation enthalpy $\left(\Delta H_{s}\right)$ of element 105 bromide

\begin{tabular}{|c|c|c|c|c|c|c|}
\hline Element & Nuclide & $\begin{array}{c}T_{1 / 2} \\
\left(=t_{r}\right)[\mathrm{s}]\end{array}$ & $\begin{array}{l}T_{50 \%} \\
{\left[{ }^{\circ} \mathrm{C}\right]}\end{array}$ & $\begin{array}{c}\Delta H_{a}^{\mathrm{a}} \\
{[\mathrm{kJ} / \mathrm{mol}]}\end{array}$ & Ref. & $\begin{array}{c}\Delta H_{s} \\
{[\mathrm{~kJ} / \mathrm{mol}]}\end{array}$ \\
\hline $\begin{array}{l}\text { Tantalum } \\
\text { Niobium } \\
105\end{array}$ & $\begin{array}{l}{ }^{166} \mathrm{Ta} \\
{ }^{99} \mathrm{~N} \mathrm{Nb} \\
{ }^{262} 105+{ }^{263} 105\end{array}$ & $\begin{array}{r}32 \\
15 \\
\approx 30\end{array}$ & $\begin{array}{l}190 \pm 40 \\
190 \pm 40 \\
320 \pm 50\end{array}$ & $\begin{array}{r}88 \pm 4 \\
85 \pm 4 \\
113 \pm 11\end{array}$ & $\begin{array}{l}\text { this work } \\
\text { Ref. [28] } \\
\text { this work }\end{array}$ & $\begin{array}{l}106^{\mathrm{b}} \\
111^{\mathrm{b}} \\
138 \pm 15^{\mathrm{c}}\end{array}$ \\
\hline
\end{tabular}

a Calculated with Eqs. (1) and (2).

${ }^{b}$ Experimental value from Ref. [35].

c Deduced from Eq. (3) as described in the text below.

$$
\begin{aligned}
& t_{r}=L T_{0} \varnothing[1+(4 / d) \\
& \left.\quad\left\{\exp \left(-\Delta H_{a} / R T\right) \exp \left(\Delta S_{a} / R\right)\right\}\right] / v_{0} T
\end{aligned}
$$

where $t_{\mathrm{r}}$ is the retention time, $T_{0}$ is $298 \mathrm{~K}, \varnothing$ is the cross section of the tube $\left(0.283 \mathrm{~cm}^{2}\right), d$ is the diameter of the tube $(0.6 \mathrm{~cm}), L$ is the length of the isothermal part of the tube $(11 \mathrm{~cm}), \Delta H_{a}$ is the adsorption enthalpy, $R$ is the gas constant $(8.31 \mathrm{~J} / \mathrm{molK}), T$ is the temperature $(\mathrm{K}), v_{0}$ is the gas flow rate $\left(18.33 \mathrm{~cm}^{3} / \mathrm{s}\right)$ and $\Delta S_{a}$ is the adsorption entropy, calculated (for mobile adsorption at a certain standard condition [15]) with

$$
\Delta S_{a}=R \ln \left[1 \mathrm{~cm}^{-1} \cdot v_{0}^{-1}(R T / 2 \pi M)^{1 / 2}\right]+R / 2
$$

where $v_{0}$ is the characteristic frequency of the adsorbent on the surface $\left(\approx 10^{12} \mathrm{~s}^{-1}\right)$ and $M$ is the mol mass of adsorbed molecules.

From the measured yield curves, the retention times $\left(t_{r}\right)$ were determined as described in Ref. [16] by taking the temperature value at a relative chemical yield of $0.5\left(T_{50 \%}\right)$ to correspond to a $t_{r}$ equal to the half-life of the nuclide. Table 1 shows the adsorption enthalpies calculated from the data depicted in Fig. 5, assuming the volatile molecules to be the pentabromides.

It is interesting to note that our $T_{50}$ values and the deduced adsorption enthalpies are higher than some literature data obtained with the gas thermochromatography technique with pure quartz columns. By intercomparison of the formulae given for gas thermochromatography [37] and for isothermal chromatography with short-lived isotopes [16] it can be shown, that $T_{A}$ should be nearly the same as $T_{50 \%}$, i.e., $T_{A} \approx T_{50 \%}$.

In our opinion, the differences between our $T_{50 \%}$ values and some $T_{A}$ values from the literature are likely to be caused by the different surfaces of the chromatographic columns. In gas thermochromatography experiments the adsorption behavior (i.e., deposition temperatures) of volatile bromides on different surfaces was studied in Ref. [38]. Besides pure quartz surfaces, also quartz columns which were coated by salts such as $\mathrm{NaBr}, \mathrm{KBr}$ and $\mathrm{CsBr}$ were investigated. The adsorption enthalpies were found to be lowest for a pure quartz surface. The deposition temperature, i.e. adsorption enthalpy, was found to increase as a function of the ionic radius of the alkali metal of the salt. The formation of mixed compounds of the type
Table 2. Adsorption temperatures, $T_{A}$, from thermochromatography (TC) experiments and retention temperatures, $T_{50 \%}$, from

\begin{tabular}{|c|c|c|c|c|}
\hline $\begin{array}{l}\text { Com- } \\
\text { pound }\end{array}$ & Surface & $\begin{array}{c}\text { Tempera- } \\
\text { ture } \\
{[\mathrm{K}]}\end{array}$ & Technique & Reference \\
\hline $\mathrm{NbBr}_{5}$ & $\mathrm{SiO}_{2}$ & 320 & $\mathrm{TC}$ & [19] \\
\hline $\mathrm{NbBr}_{5}$ & $\mathrm{SiO}_{2}$ & $398 \pm 30$ & $\mathrm{TC}$ & [38] \\
\hline $\mathrm{NbBr}_{5}$ & $\mathrm{SiO}_{2}$ & $313 \pm 10$ & $\mathrm{TC}$ & [39] \\
\hline $\mathrm{NbBr}_{5}$ & $\mathrm{SiO}_{2}$ & 315 & $\mathrm{TC}$ & [40] \\
\hline $\mathrm{NbBr}_{5}$ & $\mathrm{NiBr}_{2}$ & 325 & TC & [18] \\
\hline $\mathrm{NbBr}_{5}$ & $\mathrm{NiBr}_{2}$ & 350 & $\mathrm{TC}$ & [41] \\
\hline $\mathrm{NbBr}_{5}$ & $\mathrm{NaBr}$ & $403 \pm 30$ & TC & [38] \\
\hline $\mathrm{NbBr}_{5}$ & $\mathrm{KCl}$ & $463 \pm 40$ & IC & [28] \\
\hline $\mathrm{NbBr}_{5}$ & $\mathrm{KBr}$ & $473 \pm 15$ & $\mathrm{TC}$ & [38] \\
\hline $\mathrm{NbBr}_{5}$ & $\mathrm{CsBr}$ & $613 \pm 15$ & TC & [38] \\
\hline $\mathrm{NbBr}_{5}$ & $\mathrm{SiO}_{2} / \mathrm{C}_{2} \mathrm{H}_{6}{ }^{\mathrm{a}}$ & $450 \pm 50$ & TC & [42] \\
\hline $\mathrm{TaBr}_{5}$ & $\mathrm{SiO}_{2}$ & 335 & $\mathrm{TC}$ & [19] \\
\hline $\mathrm{TaBr}_{5}$ & $\mathrm{SiO}_{2}$ & 315 & TC & [39] \\
\hline $\mathrm{TaBr}_{5}$ & $\mathrm{NiBr}_{2}$ & 350 & TC & [41] \\
\hline $\mathrm{TaBr}_{5}$ & $\mathrm{KCl}$ & $463 \pm 40$ & IC & this work \\
\hline $105 \mathrm{Br}_{5}$ & $\mathrm{SiO}_{2}$ & $460^{-}$ & TC & [19] \\
\hline $105 \mathrm{Br}_{5}$ & $\mathrm{NiBr}_{2}$ & 450 & $\mathrm{TC}$ & [18] \\
\hline $105 \mathrm{Br}_{5}$ & $\mathrm{KCl}$ & $593 \pm 50$ & IC & this work \\
\hline
\end{tabular}
on-line isothermal chromatography (IC) for transition metal bromides of group 5 on different surfaces

This experiment was performed in a quartz column with $\mathrm{C}_{2} \mathrm{H}_{6}$ as carrier gas.

$\mathrm{KMBr}_{6}$ with $\mathrm{M}=\mathrm{Nb}$, Ta was proposed as an explanation.

In our work, the chromatography columns were fed continuously with $\mathrm{KCl}$ from the gas-jet transportation system. Since the temperature at the quartz wool plug was kept at $900^{\circ} \mathrm{C}$, the vapor pressure of $\mathrm{KCl}$ was high enough to evaporate from the quartz wool plug and to enter the isothermal section of the chromatography column. Indeed, after each experiment the columns were covered by visible amounts of white deposits. Therefore, we assume that in our experiments sorption on $\mathrm{KCl}$ was studied.

To support this interpretation we have summarized the $T_{A}$ and $T_{50 \%}$ temperatures from the literature and from this work for transition metals of group 5 bromides on different surfaces in Table 2 . The data were not corrected for minor changes of the $T_{A}$ and $T_{50 \%}$ values due to the different half-lives of the nuclides used. The corrections are expected to be less than $\pm 25^{\circ} \mathrm{C}$ [37]. The data are depicted in Fig. 7. They show that the temperatures are lowest for quartz and 


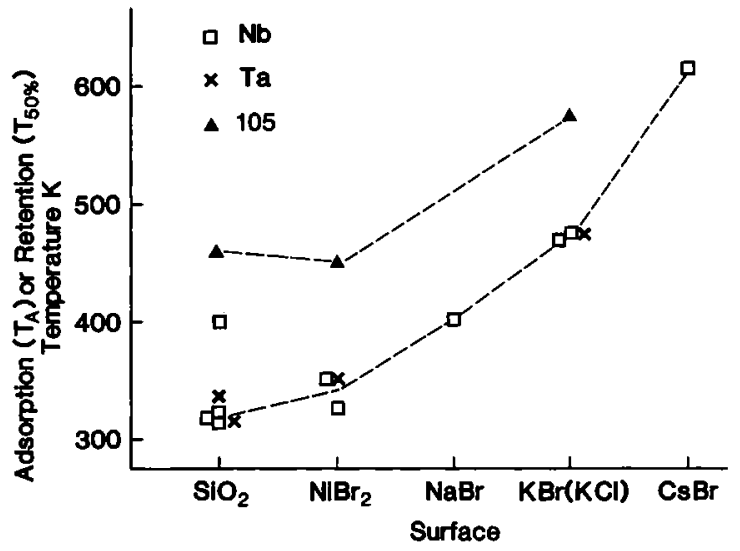

Fig. 7. Adsorption temperatures $\left(T_{A}\right)$ from gas-thermochromatography experiments and retention temperatures $\left(T_{50 \%}\right)$ from on-line isothermal gas chemistry experiments for niobium, tantalum and element 105 bromides on different surfaces, from the literature and from this work.

$\mathrm{NiBr}_{2}$ surfaces. For surfaces coated by $\mathrm{NaBr}, \mathrm{KBr}$ (or $\mathrm{KCl}$ ), and $\mathrm{CsBr}$, the $T_{A}$ and $T_{50 \%}$ temperatures are significantly higher than those for quartz. These data show a clear increase in the $T_{A}$ and $T_{50 \%}$ temperatures as a function of the radius of the metal ion $(0.72 \AA$ for $\mathrm{Ni}^{2+}, 0.95 \AA$ for $\mathrm{Na}^{+}, 1.33 \AA$ for $\mathrm{K}^{+}$, and $1.69 \AA$ for $\mathrm{Cs}^{+}$). The shift in $T_{A}$ and $T_{50 \%}$ between quartz and salt covered surfaces must be due to a change in adsorption enthalpy. For the $\mathrm{KCl}$ system, on the basis of Eq. (1) an average value for $\Delta\left(\Delta H_{a}\right) \quad\left(=\Delta H_{a}[\mathrm{KCl}]\right.$ $-\Delta H_{a}$ [Quartz]) of about $26 \mathrm{~kJ} / \mathrm{mol}$ results for $\mathrm{NbBr}_{5}$, $\mathrm{TaBr}_{5}$ and $105 \mathrm{Br}_{5}$. It is interesting to note that the reaction $\left[\mathrm{KNbCl}_{6}\right]_{s} \rightarrow[\mathrm{KCl}]_{s}+\left(\mathrm{NbCl}_{5}\right)_{g}$ is by about $40 \mathrm{~kJ} /$ mol more endothermic than the vaporization of $\mathrm{NbCl}_{5}$ (see Ref. [14]). Unfortunately, for the corresponding bromide system thermodynamic literature data are lacking.

As mentioned in the introduction, from retention data of chromatography experiments with single molecules, thermodynamic quantities of macro amounts can only be deduced on the basis of empirical rules. For bromides on quartz surfaces, the deposition temperatures in gas thermochromatography experiments were found to be proportional to the sublimation enthalpies, $\Delta H_{s}$, of the bromides [39]:

$$
T_{A}[\mathrm{~K}]=(3.3 \pm 0.3) \Delta H_{s}[\mathrm{~kJ} / \mathrm{mol}]+\text { constant. }
$$

If we assume that this empirical law also holds for surfaces different from quartz - with different values for the constant - we can determine the $\Delta H_{s}$ value for $105 \mathrm{Br}_{5}$. Based on the retention data listed in Table 1, and taking the literature values for $\Delta H_{s}$ of $\mathrm{NbBr}_{5}$ and $\mathrm{TaBr}_{5}$, one can deduce a $\Delta H_{s}$ value for $105 \mathrm{Br}_{5}$ of $138 \pm 15 \mathrm{~kJ} / \mathrm{mol}$ (see Table 1).

\section{Conclusions}

On-line isothermal gaschromatography with quartz columns was used to determine the adsorption behavior of the transition metals of group 5, niobium, tantalum, and element 105, under brominating conditions. It is assumed that the molecules investigated are the pentabromides. The retention behavior, expressed in terms of the $T_{50 \%}$ values, was found to be the same for $\mathrm{NbBr}_{5}$ and $\mathrm{TaBr}_{5}$. This is expected because of the nearly identical boiling points and sublimation enthalpies of these compounds. For element 105 bromide a stronger adsorption on the column surface is found. This can be interpreted as a lower volatility of $105 \mathrm{Br}_{5}$ compared to $\mathrm{NbBr}_{5}$ and $\mathrm{TaBr}_{5}$. Since our experiments do not allow a determination of the chemical structure of the volatile molecules passing through the column, it is possible that the studies with element 105 were made with oxy-bromides. However, the similar chromatograms observed with pure $\mathrm{HBr}$ and with $\mathrm{HBr}$ containing $\mathrm{BBr}_{3}$ vapor as reactive gas (Fig. 5) would be very surprising for oxy-bromides because $\mathrm{BBr}_{3}$ strongly reacts with trace amounts of oxygen in the system. The lower volatility of $105 \mathrm{Br}_{5}$ relative to $\mathrm{NbBr}_{5}$ and $\mathrm{TaBr}_{5}$ is at variance with theoretical expectations [11].

Since the gas-jet transport technique continuously feeds $\mathrm{KCl}$ into the quartz chromatography column we assume that the adsorption chromatography separations occurred on a $\mathrm{KCl}$ surface. This interpretation is supported by an intercomparison of our results with data from the literature (see Fig. 7).

Based on an empirical relationship in the literature between deposition temperatures from gas thermochromatographic measurements with the sublimation enthalpies for bromides [39] we deduce a sublimation enthalpy for $105 \mathrm{Br}_{5}$ of about $140 \mathrm{~kJ} / \mathrm{mol}$.

\section{Referenes}

1. Desclaux, J. P., Fricke, B.: J. Phys. 41, 943 (1980).

2. Brewer, L. J.: High Temp. Sci. 17, 1 (1984).

3. Pyykkö, P., Desclaux, J. P.: Acc. Chem. Res. 12, 276 (1979).

4. Keller, O. L.: Radiochim. Acta 37, 169 (1984).

5. Glebov, V. A., Kasztura, L., Nefedov, V. S., Zhuikov, B. L.: Radiochim. Acta 46, 117 (1989).

6. Johnson, E., Fricke, B., Keller, O. L., Nestor, C. W., Tucker, T. C.: J. Chem. Phys. 93, 8041 (1990).

7. Jost, D. T., Gäggeler, H. W., Vogel, Ch., Schädel, M., Jäger, E., Eichler, B., Gregorich, K. E., Hoffman, D. C.: Inorg. Chim. Acta 146, 255 (1989).

8. Eichler, B., Hübener, S., Gäggeler, H. W., Jost, D. T.: Inorg. Chim. Acta 146, 261 (1989).

9. Zhuikov, B. L., Glebov, V. A., Nefedov, V. S., Zvara, I.: J. Radioanal. Nucl. Chem. 143(1), 103 (1990).

10. Pershina, V., Sepp, W. D., Fricke, B.: Scientific Report 1990 Gesellschaft für Schwerionenforschung mbH, Darmstadt, GSI-91-1, p. 274 (1991), unpublished.

11. Pershina, V., Sepp, W. D., Fricke, B.: Scientific Report 1990, Gesellschaft für Schwerionenforschung mbH, Darmstadt, GSI-91-1, p. 275 (1991), unpublished.

12. Guillaumont, R., Adloff, J. P., Peneloux, A., Delamoye, P.: Radiochim. Acta 54, 1 (1991).

13. Zvara, I.: Pure Appl. Chem. 53, 979 (1981).

14. Zvara, I., Chuburkov, Yu. T., Belov, V. Z., Buklanov, G. V., Zakhvataev, B. B., Zvarova, T. S., Maslov, O. D., Caletka, R., Shalaevski, M. R.: J. Inorg. Nucl. Chem. 32, 1885 (1970).

15. Eichler, B., Zvara, I.: Radiochim. Acta 30, 233 (1982). 
16. Gäggeler, H., Dornhöfer, H., Schmidt-Ott, W. D., Greulich, N., Eichler, B.: Radiochim. Acta 38, 103 (1985).

17. Zvara, I., Belov, V., Korotkin, Yu. S., Shalayevski, M. R., Shchegolev, V. A., Hussonois, M., Zager, B. A.: Report JINR P12-5120, Dubna (1970).

18. Zvara, I., Belov, V. Z., Domanov, V. P., Shalaevskii, M. R.: Radiokhimiya 18(3), 371 (1976).

19. Zvara, I., Timokhin, S. N., Chuburkov, Yu. T., Yakushev, A. B., Gorki, B.: Joint Institute for Nuclear Research, Laboratory for Nuclear Reactions, Dubna, Scientific Report 1989-1990, E7-91-75, p. 36f (1991), unpublished.

20. Gregorich, K. E., Henderson, R. A., Lee, D. M., Nurmia, M. J., Chasteler, R. M., Hall, H. L., Bennett, D. A., Gannet, C. M., Chadwick, R. B., Leyba, J. D., Hoffman, D. C., Herrmann, G.: Radiochim. Acta 43, 233 (1988).

21. Kratz, J. V., Zimmermann, H. P., Scherer, U. W., Schädel, M., Brüchle, W., Gregorich, K. E., Gannett, C. M., Hall, H. L., Henderson, R. A., Lee, D. M., Leyba, J. D., Nurmia, M. J., Hoffman, D. C., Gäggeler, H., Jost, D., Baltensperger, U., Ya Nai-Qi, Türler, A., Lienert, Ch.: Radiochim. Acta 48, 121 (1989).

22. Weis, M., Ahrens, H., Denschlag, H. O., Fariwar, M., Herrmann, G., Trautmann, N.: Radiochim. Acta 42, 102 (1987).

23. Gober, M. K., Kratz, J. V., Zimmermann, H. P., Schädel, M., Brüchle, W., Schimpf, E., Gregorich, K. E., Türler, A., Hannink, N. J., Czerwinski, K. R., Khadkhodayan, B., Lee, D. M., Nurmia, M. J., Hoffman, D. C., Gäggeler, H., Jost, D., Kovacs, J., Scherer, U. W., Weber, A.: Radiochim. Acta 57, 77 (1992).

24. Gäggeler, H. W., Jost, D. T., Baltensperger, U., Ya Nai-Qi, Gregorich, K. E., Gannett, L. M., Hall, H. L., Henderson, R. A., Lee, D. M., Li, J. D., Nurmia, M. J., Hoffman, D. C., Türler, A., Lienert, Ch., Kratz, J. V., Zimmermann, H. P., Scherer, U. W.: Report Paul Scherrer Institut PSI-49 (1989).

25. Türler, A., Gäggeler, H. W., Gregorich, K. E., Barth, H., Brüchle, W., Czerwinski, K. R., Gober, M. K., Hannink, N. J., Henderson, R. A., Hoffman, D. C., Jost, D. T., Kacher, C. D., Kadkhodayan, B., Kovacs, J., Kratz, J. V., Kreek, S. A., Lee, D. M., Leyba, J. D., Nurmia, M. J., Schädel, M., Scherer, U. W., Schimpf, E., Vermeulen, D., Weber, A., Zimmermann, H. P., Zvara, I.: Proc. MARC II Conf., Kona, Hawaii, April 1991, J. Radioanal. Nucl. Chem., in press.
26. Gäggeler, H. W., Jost, D. T., Baltensperger, U., Weber, A., Kovacs, A., Vermeulen, D., Türler, A.: Nucl. Instrum. Methods A309, 201 (1991).

27. Kratz, J. V., Gober, M. K., Zimmermann, H. P., Schädel, M., Brüchle, W., Schimpf, E., Gregorich, K. E., Türler, A., Hannink, N. J., Czerwinski, K. R., Kadkhodayan, B., Lee, D. M., Nurmia, M. J., Hoffman, D. C., Gäggeler, H., Jost, D., Scherer, U. W., Weber, A.: Phys. Rev. C, 45, 1064 (1992).

28. Ya Nai-Qui, Jost, D. T., Baltensperger, U., Gäggeler, H.: Radiochim. Acta 47, 1 (1989).

29. Schlepütz, F. W.: IEEE Trans. Nucl. Sci. 36(5), 1630 (1989).

30. Brun, R.: CERN program library entry Q121, CERN Geneva (1989).

31. Jost, D. T., Vermeulen, D.: Proc. $7^{\text {th }}$ Conf. REAL TIME, Jülich, June 1991; Preprint Paul Scherrer Institut, Villigen, PSI-91-15 (1991); IEEE Trans. Nucl. Sci., in press.

32. Gäggeler, H., Jost, D., von Gunten, H. R.: Measurement of above target cross sections from the reaction ${ }^{18} \mathrm{O}+{ }^{249} \mathrm{Bk}$, Internal Report Eidg. Institut für Reaktorforschung, Würenlingen, TM-44-87-04 (1987), unpublished.

33. Ghiorso, A., Nurmia, M., Eskola, K.: Phys. Rev. C4, 1850 (1971).

34. Gregorich, K. E.: Nucl. Instrum. Methods A302, 135 (1990).

35. Handbook of Chemistry and Physics, CRC Press, $55^{\text {th }}$ Ed. (1975).

36. For an intercomparison of chlorides and oxy-chlorides, see: V. P. Domanov, U. J. Kim, S. S. Bedronosov, I. A. Kopylova, V. Ya. Lebedev, Report JINR, P6-88-633, Dubna (1988).

37. Eichler, B., Gäggeler-Koch, H., Gäggeler, H.: Radiochim. Acta 26, 193 (1979).

38. Tsalas, S., Bächmann, K., Heinlein, G.: Radiochim. Acta 29, 217 (1981)

39. Kim, U. J., Timokhin, C. N., Zvara, I.: Isotopenpraxis 24(1), 30 (1988).

40. Zvara, I., Keller, O. L., Silva, R. J., Tarrant, J. R.: J. Chromatogr. 103, 77 (1975).

41. Belov, V. Z., Zvarova, T. S., Shalaevski, M. R.: Report JINR P12-8216, Dubna (1974).

42. Silva, R. J., Trautmann, N., Zendel, M., Dittner, P. F., Stender, E., Ahrens, H.: Nucl. Instrum. Methods 147, 371 (1977). 